\title{
Calcified unruptured aneurysm of sinus of Valsalva with complete heart block and aortic regurgitation Successful repair in one case
}

\author{
D METRAS, A O COULIBALY, K OUATTARA \\ From the Institute of Cardiology, Abidjan Department of Surgery, Ivory Coast
}

SUMMARY A case is presented of a calcified aneurysm of the sinus of Valsalva extending into the interventricular septum. Complete atrioventricular block and aortic regurgitation were associated. The patient, a 37 year old black African, was successfully operated upon by patch closure of the orifice of the aneurysm, aortic valve replacement, and permanent pacemaker insertion.

We report a patient with a calcified unruptured aneurysm of the right coronary sinus of Valsalva, with an extension into the interventricular septum producing complete heart block and aortic regurgitation. Successful surgical repair was achieved by patch closure of the aneurysm, aortic valve replacement, and permanent pacemaker insertion.

\section{Case report}

A 37 year old black African man was first admitted to the hospital in 1975. At this time moderate aortic regurgitation was recognised. The patient was in functional class II, had moderate cardiomegaly (cardiothoracic ratio: 0.56 ), with a calcified contour in the area of aortic root, and electrocardiographic findings consistent with trifascicular block. Cardiac catheterisation and aortography showed moderate aortic regurgitation. Because of the quality of the angiogram at that time, the aneurysm of the sinus of Valsalva was not clearly identified. The patient was readmitted in 1977 because of complete heart block and a transvenous pacemaker was inserted. In December 1980, he was again readmitted with increasing dyspnoea. There were no signs of congestive heart failure but a slow heart rate was present and on auscultation a grade $3 / 6$ diastolic murmur was heard. The electrocardiogram confirmed that the heart was paced at 60 beats a minute. There was cardiomegaly on chest $x$-ray (cardiothoracic ratio: 0.70). As in 1975, the same calcified contour of the aortic root was visible (Fig. 1). The patient had a temporary pacemaker lead inserted, and underwent catheterisation. Right atrial and ventricular pressures were normal. In the aorta, the systolic pressure was $160 \mathrm{mmHg}$, the diastolic 60 $\mathrm{mmHg}$. The left ventricle could not be entered. The cardiac output was $2.24 \mathrm{l} / \mathrm{min}$ and the cardiac index was $1.4 \mathrm{l} / \mathrm{min}$ per $\mathrm{m}^{2}$. The aortic angiograms showed moderate to severe aortic regurgitation; a large nonpulsatile aneurysm of the sinus of Valsalva, with calcified borders; the origin of the aneurysm could not be clearly determined but there was an extension of the aneurysm into the interventricular septum. This extension was pulsatile and had not ruptured into a cardiac cavity (Fig. 2).

At operation, after establishment of cardiopulmonary bypass between the venae cavae and the ascending aorta, with moderate hypothermia, aortic cross-clamping, cardioplegia, and topical hypo-

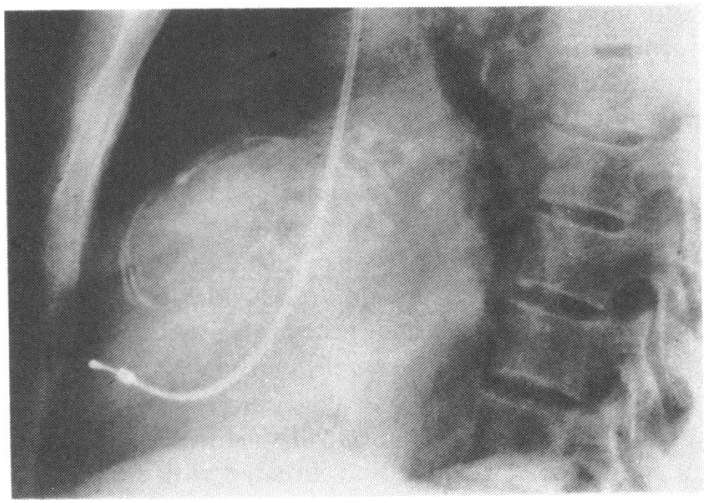

Fig. 1 Lateral chest $\mathrm{x}-\mathrm{ray}$. The calcified border of the aneurysm is clearly seen in the area of the aortic orifice. 


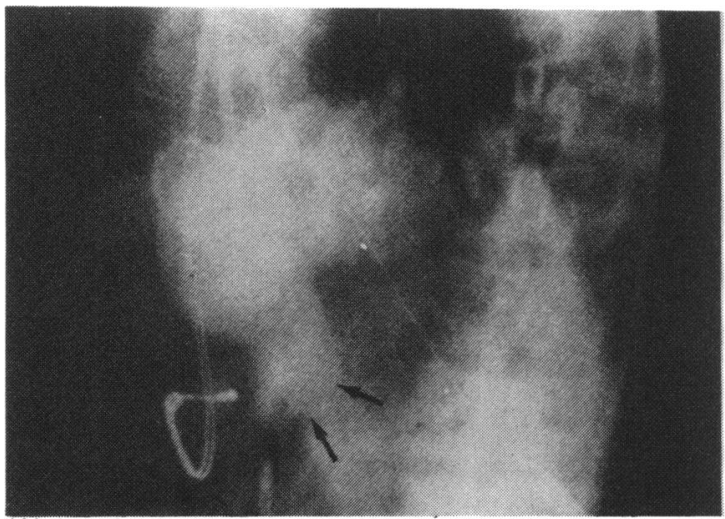

(A)

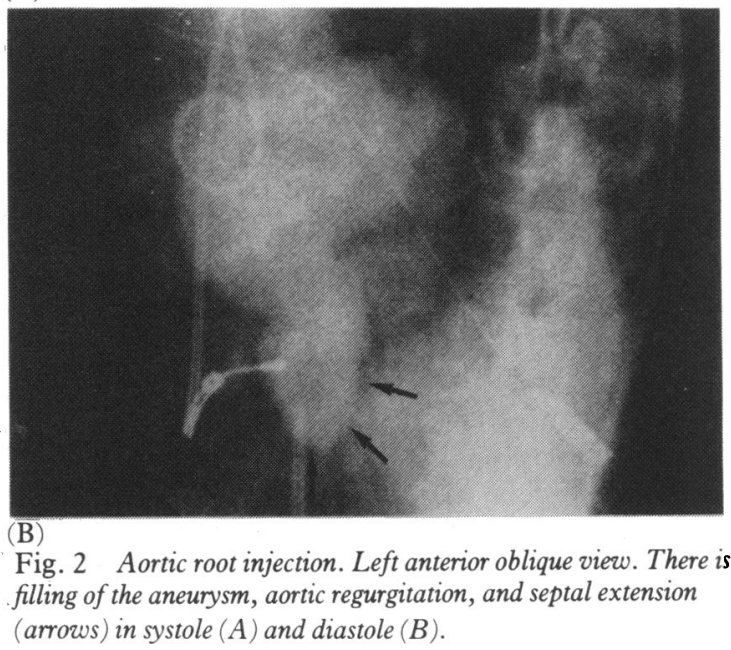

thermia, the ascending aorta was incised. The following lesions were recognised: (1) aortic regurgitation by upward displacement of the right coronary cusp, with dilatation of the annulus. The aortic cusps were not deformed; (2) a $20 \mathrm{~mm}$ diameter orifice was seen in the right coronary sinus of Valsalva, adjacent to the aortic annulus; the right coronary artery orifice was lifted up and located $10 \mathrm{~mm}$ above the superior aspect of this orifice; (3) the aneurysm itself was entirely calcified, and defined a semicircle about the subaortic area of the left ventricle. It was visible in the upper septal part, below the right coronary cusp, partially obstructing the subvalvular area. It did not, however, produce significant left ventricular outflow tract obstruction.

A Dacron patch was used to close the orifice of the sinus of Valsalva using a continuous prolene suture (because of the calcification, this orifice was rigid, and its edges could not be approximated with suture technique alone). The aortic valve was replaced with a xenograft. The interrupted sutures of the valve were difficult to place at the level of the calcified edge of the aneurysm of the sinus of Valsalva orifice. Finally, an asynchronous permanent pacemaker was implanted with epicardial wires.

The patient was difficult to wean off cardiopulmonary bypass, and adrenaline and dopamine were used, inotropic drugs being continued for $\mathbf{4 8}$ hours, and the patient was maintained on a volume respirator for 36 hours after operation. The subsequent postoperative course was smooth. Two weeks after operation, however, a diastolic murmur, grade 1 to $2 / 6$, appeared suggesting a paravalvar leak. An aortic root angiogram was performed, and showed minimal aortic regurgitation. The aneurysm of the sinus of Valsalva was no longer filled by the contrast medium (Fig. 3). The patient was discharged on the 37th postoperative day on digoxin. Since that time, the patient has been seen at the clinic: he is in functional class 1 , with persistence of grade $2 / 6$ diastolic murmur. Heart size has decreased (cardiothoracic ratio: 0.60). Because of his excellent functional tolerance, reoperation for the paravalvar leak has not been contemplated.

\section{Discussion}

The extension of an unruptured aneurysm of the sinus of Valsalva into the interventricular septum is extremely rare. In the seven reported cases ${ }^{1}$ the origin of the aneurysm was in the right coronary sinus. The mechanism for septal extension has been ascribed to simple progression, intraseptal rupture with haematoma and subsequent pseudo aneurysm, and bacterial endocarditis. ${ }^{2}$ This septal extension has been reported to present as mitral regurgitation because of displacement of the anterior mitral leaflet. ${ }^{2}$ In our case the cause for the septal extension could not be clearly identified, since the calcified aneurysm was fragile and was not manipulated.

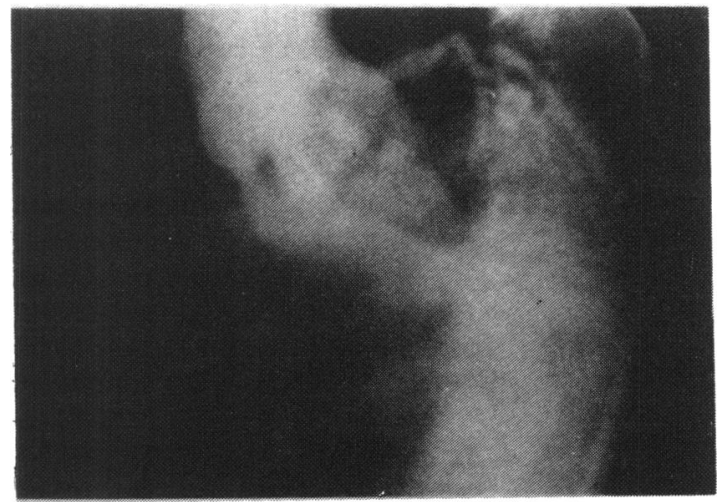

Fig. 3 Postoperative root injection. Left anterior oblique view. There is minimal aortic regurgitation. The aneurysm is no longer filled. The radiolucency corresponds to the xenograft. 
In the seven cases reported, there were conduction disturbances. There were four cases of complete heart block, two resulting in the death of the patient. The mechanism for atrioventricular block is easily explained by extension of the sinus of Valsalva aneurysms to the vicinity of the conduction tissue. In the two deaths reported, 13 haemorrhagic and inflammatory lesions were found in the area of the bundle of His. The presence of atrioventricular block, however, does not necessarily mean septal extension. In the most frequent type of aneurysm of the sinus of !Valsalva (right coronary sinus) the proximity of the $_{\mid}$conduction tissue may lead to conduction disturbances. ${ }^{2}$

In our patient, we have observed progressive evolution of the aberrant conduction (trifascicular block in 1975, complete heart block in 1977 needing the pacemaker implantation). This may be the result of the progression of the septal extension, since the aneurysm was already present in 1977.

Aortic regurgitation, minimal to severe, is present in the majority of cases of aneurysm of the sinus of Valsalva, whether ruptured or not. ${ }^{46} 6$ The mechanism for aortic regurgitation is variable but usually includes prolapse ${ }^{4}$ and/or a fibrous thickening of the aortic cusp which is displaced by the aneurysm. Lesions of rheumatic origin and congenital absence of one cusp ${ }^{1}$ have also been reported. Aortic regurgitation does not always necessitate valve replacement. ${ }^{4}$ When it is possible to approximate the edges of the orifice, thus reinforcing the aortic annulus, such valve replacement can be avoided. In our case, the calcification of the entire aneurysm rendered approximation of the edges of the orifice impossible and the cusps were too displaced, despite anatomical integrity, to be retained. Difficulties of suture technique caused by severely calcified edge of the aneurysm were probably responsible for the physiologically insignificant paravalvar leak that we observed.

Calcifications of a sinus of Valsalva aneurysm have been reported very rarely. We found only one case ${ }^{7}$ where a calcified aneurysm was reported to have ruptured into the left ventricle without aortic valvar regurgitation. This case occurred also in a black African. The mechanism of calcification is probably similar to the calcification of the left ventricular subannular aneurysms reported in the black African in Nigeria. ${ }^{8}$ Several reasons have been advocated: infectious, viral, parasitic, hereditary, or nutritional factors. The iactual mechanism is unknown. The consequences of these calcifications, when present, are favourable haemodynamically since there is less ventricular dyskinesia because of the rigidity of the aneurysm. In the above-mentioned case, as in our case, the friable calcification rendered any direct surgical approach to the aneurysm dangerous. Furthermore, in our case, the location of the aneurysm encircling the left ventricular outflow tract reinforced this danger and precluded its resection.

\section{References}

1 Rozensztajn L, Jaillon P, d'Allaines C, et al. Anevrysme congenital non rompu du sinus de Valsalva propage dans le septum interventriculaire avec insuffisance aortique et bloc auriculo-ventriculaire. Coeur 1975; 6: 891-905.

2 Soulié P, Daumet P, Caramanian M, Soulié J, Heulin A. Anévrisme du sinus de Valsalva propagé dans le septum interventriculaire. Arch Mal Coeur 1969; 62: 597-616.

3 Lee EB, Krieger OJ, Lee NK. Congenital aneurysm of the non coronary sinus of Valsalva leading to complete heart block: case report. Ann Intern Med 1956; 45: 525-34.

4 Taguchi K, Sasaki N, Matsuura Y, Vemura R. Surgical correction of aneurysm of the sinus of Valsalva. A report of 45 consecutive patients including 8 with total replacement of the aortic valve. Am $\mathcal{F}$ Cardiol 1969; 23: 180-91.

5 London SB, London RE. Production of aortic regurgitation by unperforated aneurysm of the sinus of Valsalva. Circulation 1961; 24: 1403-6.

6 Acar J, Cartier F. Les anévrysmes congénitaux des sinus de Valsalva. Coeur Med Interne 1964; 3: 39-56.

7 Bex JP, Bertrand E, Neveux JY, Renambot J, Hvass U. Rupture d'un anevrisme du sinus de Valsalva anterogauche dans le ventricule gauche chez un malien de 24 ans. Médecine d'Afrique Noire 1975; 22: 525-7.

8 Cockshott WP, Antia A, Ikeme A, Uzodike VO. Annular subvalvar left ventricular aneurysms. Brf Radiol 1967; 40: 424-35.

Requests for reprints to Dr D Metras, Institute of Cardiology, BP V 206 Abidjan, Ivory Coast. 